\title{
Abstract assessment of knowledge, attitude and risk practice for HIV infection among male prisoners: the case Maweni prison, Tanga region Tanzania
}

Joan Karomba

From $16^{\text {th }}$ International Symposium on HIV and Emerging Infectious Diseases

Marseille, France. 24-26 March 2010

\section{Background}

HIV prevalence in prisons has been reported to be higher compared to general population. However, prisoners have been overlooked and little has been done regarding HIV in this high risk group.

Attitude and practice studies are crucial to acquire information that would be required to plan for the appropriate intervention programs that would be used to reduce risk practice among this high group. This study aimed to assess knowledge attitude and risk practice related to HIV infection among inmate prisoners.

\section{Methods}

This was a cross sectional analytical study design was conducted from April to May 2009. Structured questionnaires were used to collect relevant information from the participants through face to face interview. A systematic random sampling was used to select 203 male prisoners to participate in this study. Ethical approval was obtained before commencing this study from the Muhimbili college research ethics committee, permission to conduct the study was sought from prisons authority and informed consent was obtained from the study participants.

Statistical Package for Social Sciences (SPSS) program version 14.0 was used to analyze data. Median range and proportions for different variables were estimated

\section{Results}

About 100 (50.3\%) of the study participants have high knowledge on HIV infection, 107 (53.8\%) of the participants have negative attitude toward HIV prevention and 106 (53.2\%) of the participants have HIV risk practice related to HIV infection. However risk practice have statistical significant association with knowledge on HIV infection $(\mathrm{P}=0.001)$ and attitude towards HIV prevention $(\mathrm{p}=0.02)$

\section{Discussion}

Participants have high HIV risk practice which could have been contributed by low knowledge on HIV infection and negative attitude toward HIV prevention. The most important area to think about when plan for intervention should base on increase level of knowledge on HIV infection to alter negative attitude towards HIV prevention and to reduce risk practice related to HIV infection.

\section{Recommendation}

HIV health education in prison must become a public health priority to educate prisoners through.

Published: 11 May 2010

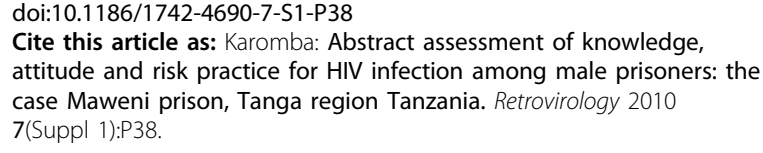

